Provided for non-commercial research and educational use. Not for reproduction, distribution or commercial use.

This article was originally published in the Encyclopedia of Consciousness published by Elsevier, and the attached copy is provided by Elsevier for the author's benefit and for the benefit of the author's institution, for noncommercial research and educational use including without limitation use in instruction at your institution, sending it to specific colleagues who you know, and providing a copy to your institution's administrator.

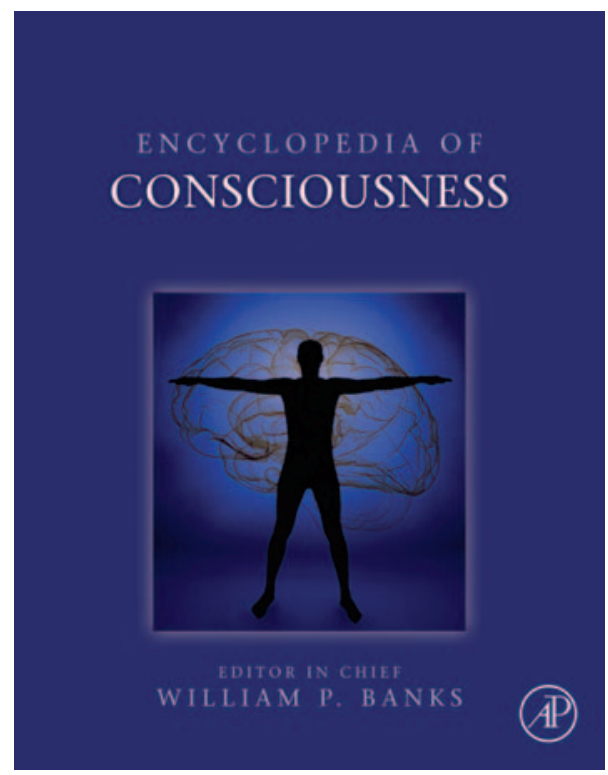

All other uses, reproduction and distribution, including without limitation commercial reprints, selling or licensing copies or access, or posting on open

internet sites, your personal or institution's website or repository, are prohibited. For exceptions, permission may be sought for such use through Elsevier's permissions site at:

http://www.elsevier.com/locate/permissionusematerial

Hirstein W and Campbell M (2009), Aesthetics and the Experience of Beauty. In: William P. Banks, (Editor), Encyclopedia of Consciousness. volume 1, pp. 1-7. Oxford: Elsevier. 


\title{
Aesthetics and the Experience of Beauty
}

\author{
W Hirstein, Elmhurst College, Elmhurst, IL, USA \\ M Campbell, National University, La Jolla, CA, USA
}

(c) 2009 Elsevier Inc. All rights reserved.

\section{Glossary}

Neuroaesthetics $-A$ research paradigm whose proponents attempt to learn more about the human aesthetic experience by studying the brain, in particular the perceptual system.

\section{Introduction}

What is required for aesthetic experience to take place? Who or what is capable of having aesthetic experience and of judging something to be beautiful? A wild wolf surveying the canyon floor for small moving prey is in an exquisitely sensitive perceptual state, but he is not having an aesthetic experience. Is aesthetic experience solely the province of humans, then? Is there no animal model of our appreciation of art? Or what about the nest of the bowerbird, discussed by Ernst Gombrich in his study of the psychology of decorative art? Gombrich compares the sorts of repetitive patterns and color arrays with no underlying meaning beyond their visual impact found in decorative art with products found in the animal world. He points to the example of the nest of the bowerbird, known for creating highly decorated nests made complex (and beautiful?) with shells, brightly colored objects such as berries, feathers, flowers, and even found items of human manufacture such as plastic or glass. Not only does the male bird spend many hours building, creating, and crafting the nest, but he will also replace moved or disturbed elements of a seemingly intentional design. Moreover, each bower built is completely original and reflects decisions made by its creator on the type, color, and structural array of objects collected for decorating the nest. Should we say that these birds are artists? Should we attribute the capacity of aesthetic judgment to the female bowerbirds who select their mate on the basis of the brilliance of his bower?

In the human realm, our aesthetic drive seems to predate history at the very least. Paleolithic people imprinted cave walls with figures, symbols, and what seem to be projected forms of internal images. It is not known whether the underground paintings at Chauvet cave or Lascaux, France, are truly works of art, products of an 'aesthetic impulse,' or just primitive attempts at magical wish-fulfillment, but they clearly arouse aesthetic responses in modern-day viewers who marvel at their beauty and elegance. Principled reflection on the concept of the aesthetic response and on its relation to cognition probably starts with the ancient Greek philosophers Plato and Aristotle, who each had something to say about aesthetics (from the Greek, aisthanomai and aesthetikos, perception or apprehension through the senses). Plato holds beauty itself in the highest regard, as an eternal aspect akin to virtue and truth. However, Plato has something quite different to say about the experience of beauty as effected through perceptual activity, and we get a sense of his displeasure by noting his censure of those who would attempt to play with our sensory intake and manipulate the quality of perceptual experience artists - who deal in images, representations, and analogies, but not, as Plato would claim, unfiltered truth. Unlike Plato, Aristotle sees a place for the arts and the development of aesthetics as worthwhile imitations of life and its passions: The arts can provide an occasion for katharsis, a purging of emotions through vicarious experience.

The field of aesthetics comes into its own in the eighteenth century when Alexander Baumgarten, a German rationalist philosopher, resurrected the term 'aesthetics' from the earlier Greek usage to serve as the label for a philosophical discipline dealing with knowledge from sensory perception. 
Another eighteenth-century thinker, Immanuel Kant, realized that sensory experience, in all its complex and concept-defying richness, requires its own methods of discovery and analysis. Turning his thinking to aesthetics, Kant distinguishes three types of aesthetic, or reflective, judgments based on feelings of pleasure or displeasure: judgments of the agreeable, judgments of the beautiful (or of taste), and judgments of the sublime. In deeming something agreeable, one is merely attributing to it a subjectively determined pleasure-producing quality. We do not expect others to find it so; we would call something agreeable 'beautiful' only in this limited and nonbinding sense. Notions of the sublime go beyond the concept of beauty: The sublime is aweinspiring, fearsome, overwhelming. Turning to judgments of beauty, Kant mentions four aspects that are essential to such judgments: (1) disinterested pleasure (we find pleasure in the object because it is beautiful, not the other way around); (2) universal validity (but this universality is not based on any kind of rigid conceptual categorization); (3) something he calls 'purposeless purposiveness' (the result of 'free play' of the imagination); and (4) necessity (a subjective attribution of beauty exemplifies how the object ought to be judged).

\section{Aesthetic Perception}

Aesthetic judgments, although grounded in sensory cognition, differ in the role they play in human experience. Beyond enabling the attribution of properties such as shape, color, odor, texture, and so forth to particular things, aesthetic judgments allow us to ascribe meaning and value to experiences. Not only is a sample of Chateau Lafite wine pungently fragrant, purplish red, tart, and cool, a sip of it delivers a highly complex blend of aromas and flavors that can be named only by comparison to mundane substances: oak, cherry, smoke, chocolate. The experience of the connoisseur supervenes on the base elements of taste and smell, but there is more: He transforms these elements into something new through the prism of his cognitive stock - his knowledge that the wine is rare, outrageously expensive, and coveted by experts - along with his memories of having drunk other rare wines and his feelings of anticipation fueled by imagining the pleasure to come.

Qualities in nonhuman creatures that attract mates (or in some cases frighten away predators) may be compared with those qualities which, at first glance, comprise human beauty or attractiveness. But again, at least in the case of humans, the aesthetics of beauty require more than recognition of forms and sounds and perception of colors and odors. The appreciation of beauty involves conscious activity in which areas of the brain are engaged in the production of a complex mental state - a hybrid of sensory and cognitive components. Recent research on the facial characteristics we consider beautiful has found that symmetric faces are judged to be more beautiful than asymmetric ones. Of course, perfect faces can be boring, and introducing asymmetries or flaws can improve on perfection. We call a single dark mole on one side of a woman's mouth a 'beauty mark,' but correct the asymmetry by placing a matching mole on the opposite side, and we see the pair as a sort of disfigurement. The single mole reorganizes our perception of her face by accentuating certain features and drawing attention away from others. Our understanding of how we read emotions from faces is also progressing nicely, and much of this information is relevant to the artistic expression of emotion through the depiction of faces, such as the Mona Lisa's intriguing smile. By steadily understanding the processes behind our perception of emotion and attractiveness in faces, we can both come to understand those judgments and teach the artist the dimensions along which faces vary. Many visual artists, particularly painters of the Impressionist and post-Impressionist periods of the late eighteenth and early twentieth centuries, are interested in understanding and exploiting the workings of the eye and brain in perceiving light and constructing colors.

\section{Aesthetics and Neurophysiology}

The early findings of the Gestalt psychologists demonstrate that our visual systems will complete gaps in lines and corners, fill in colors, and so on in order to produce a more unified and coherent perceptual end-product. We have reached the point where we can provide neuroscientific 
explanations of these Gestalt phenomena, something that seems to invite the possibility of our gaining a neuroscientific understanding of more complicated perceptual events such as those involving the perception and aesthetic appreciation of works of art. The new science of neuroaesthetics investigates perception and the way the brain generates aesthetic responses. How are forms and patterns processed? Are certain forms 'preferred' over others by the perceptual system?

Neuroaesthetics has produced two early theories of how the brain generates aesthetic responses. Semir Zeki has developed a theory of aesthetics that appeals to neurophysiological structures and events in the human brain, and he goes some distance beyond well-established claims that they are essential in expounding or expanding traditional ideas about painting as an art. Zeki asserts that artists, because they study the brain and the mechanisms of perception and the causal avenues for producing aesthetic responses, are themselves neurologists. Where a painter differs from a scientist who studies visual perception is in methodology, not in subject matter, according to Zeki. Viewing the work of visual artists from Zeki's perspective provides a deeper insight into why an artist does what he does in constructing a painting, why he chooses the exact shapes, colors, and specific juxtapositions of painterly elements such as line, shading, perspective, and so on. The artist is exploring, exploiting, challenging, and manipulating the brain's ability to absorb and interpret sensory data in novel, unexpected, and exciting ways. Therein lies the basis of the aesthetic response; not only does the spectator see shapes, lines, and colors of various tints and shades when he or she looks at a painting, but there is also the essential component of any successful work of art that is the production of a type of mental state that outstrips ordinary perception. Great, or even good, art will arouse subtle, or perhaps strong, emotions. It will jostle and arouse memory and effect numerous associations with other mental states. It can induce a sense of joy or of infinite sorrow; it may even lift the spectator to heights of spiritual or existential transcendence. And the artist accomplishes all this without electrodes, probes, or chemicals. The artist, in Zeki's view, is a virtuoso scientist using instruments much simpler and less invasive, but requiring great ingenuity and immense perspicacity in their application.

Zeki emphasizes the analogy between the way that our perceptual systems function to extract the more permanent patterns in the flow of energy reaching them with the way that artists often strive to capture the essence of objects they depict. Ramachandran argues further that the representational artist is presenting us with a sort of caricature of the represented object, in which certain perceived features have been exaggerated while other features have been deemphasized. A skilled artist can evoke a particular person or place with a few deftly drawn lines, using the art of caricature to capture a sort of 'formal essence' of the represented person or thing. What we are able to see through such caricatures depends, in scientifically describable ways, on the structure of our visual system and its connections to the different memory systems. Much of visual art can be captured by rules of form, many of which are derived from the findings of the Gestalt psychologists, such as symmetry, balance, and grouping of forms. Artists combine these basic form-primitives in new and evocative ways, according to Ramachandran.

\section{Consciousness and Aesthetic Experience}

What is the connection between consciousness and aesthetic experience? Are aesthetic experiences necessarily conscious, for instance? While it may be no easier to show the necessity of consciousness to aesthetic experience than to any other sort of experience or mental function, aesthetic experiences are often included in lists of paradigm conscious experiences. It is also interesting to note that several of the classic puzzles that theorists of consciousness are tasked to solve either make reference to aesthetic reactions themselves, or to their essential ingredients, such as the ability to perceive color, as in Frank Jackson's 'Mary case.' Mary is a future neuroscientist who knows about all of the physical processes involved in human color vision, but has never seen any colors other than black and white (she is kept in a special room, only given certain foods, etc.). When Mary is 
finally allowed to see colors, she seems to learn something new, that is, what it is like to consciously experience red. But she already knew about all the physical events involved, and so there appears to be a problem for theorists who claim that the mind is physical, in that the conscious experience of red seems not to be among the physical events that we agreed initially that Mary knew. Another classic puzzle, Dennett's 'Chase and Sanborn problem,' involves something close to aesthetic perception - in this case, coffee tasting. Chase and Sanborn have been brewing their coffee for decades, but neither of them likes the taste any longer. Chase says that his taste preferences have not changed over time, but that the way the coffee tastes to him has changed. Sanborn says that the coffee tastes the same to him, but his preferences have changed so that he no longer enjoys that flavor. Dennett claims that no physicalist theory can capture the difference between Chase and Sanborn, because he believes that the taste and the preference for the taste cannot be teased apart. Delving further into the distinction between perception and preference, and whether and how it might be made, will also reveal information of interest about art. Indeed, to pose a final neuroaesthetic theory of the experience of art, the scientist may have to wait until these more basic ontological questions are answered.

But must aesthetic experiences be conscious? Could there be a zombie artist, for instance, a being who looks and acts just like a normal person, creating and appreciating works of art but not capable of consciousness? But, is not the whole point of creating works of art to produce those special conscious experiences? What is the point of his making these objects, we want to know. We might look more closely into our normal aesthetic experience for unconscious events that are at least important to our experiences, if not outright components of it. One candidate for an unconscious aesthetic response is the sort of case where, for example, one realizes some time after seeing a film an interesting subplot of which he had not been conscious aware on first seeing the film. In more complicated artworks, especially of the narrative variety such as the novel, how the author handles the main plot and its relations to various subplots is an important part of how we aesthetically evaluate such works. In cases like the film viewer who only later fully appreciates the work, the brain seems to be continuing the attempt to understand the artwork all on its own. Certainly many artists have reported being inspired by dreams, although it is debatable whether dreams themselves are a type of conscious state.

Consciousness relates to aesthetic experience at two basic points, which then can permute and recombine to produce more complex aesthetic experiences. The first point of contact concerns the artist's act of creation, including the intentions specifying how the artwork will be made and what the end result will (ideally) be like. The second point of contact concerns the conscious perception of the finished artwork by a human perceiver. One of the first recombinations of these basic ingredients occurs in the brain of this viewer when she considers the intentions of the artist. There is also the fact that many artists attempt to emulate the mind of a viewer, or often more specifically, viewers of different sorts: critics, peers, average people, etc. So the viewer is modeling the intentions of the artist, while the artist is modeling the understanding of the viewer. This sort of activity falls under the category of 'theory of mind' or 'mindreading'; in this case intentions and perceptual states are modeled. Another kind of reading we do of other people occurs when we watch their intentional activities while employing mirror neurons to understand their actions. Rizzollati, who is the first to attribute the familiar imitative behavior we observe not just in monkeys but in humans as well to these specialized 'mirror neurons,' notes that mirror neurons are at their most effective when the observer is face-toface with the observed. Stafford suggests that this fact explains why so many visual artists focus on the face as the center of a work, sometimes presenting the viewer with nothing but a face. Here the artist is playing up the natural emphasis on frontality and the intuitive recognition that some of our most deep-seated reflections about who people are, about our own identity, arise from contemplating the face of the other, or of the face in the mirror.

Several neurological patients have recently been described who have become obsessed with art after brain lesions, or repeated epileptic seizures, very often in the temporal lobes. These obsessions typically focus on a particular medium, often painting 
or music. The obsessions can compel the patient to spend every waking moment creating and performing art, and some of the patients have become quite accomplished and are even able to sell paintings for high prices, or impress music critics with their composition or performances. Apparently, these patients find thinking about and creating works of art extremely rewarding, so much so that they sometimes forget to eat while in the throes of creation. This suggests an explanation for aesthetic responses that relates them to consciousness in general. There is little point in assembling the expensive and complicated machinery needed to achieve consciousness if we do not trouble ourselves to use it. Perhaps because conscious thinking requires effort, there needs to be a reward for engaging in conscious thought. Nature's way of enticing us toward conscious activity, according to this view, is to make conscious experience itself rewarding. Contemplation of the contents of consciousness is not, as we might have thought, basically neutral, with any emotional response being traceable to the particular contents of that mental state and not to consciousness itself, but rather pleasurable in itself. Sometimes, naturally, the particular contents of consciousness are unpleasant enough to cancel out this basically positive reaction, as usually happens in the case of pain experience, for instance. One perhaps sees a similar 'enticement' mechanism at work in the case of sex; nature entices us to use our sexual organs so that the race proliferates by making their use highly rewarding. It seems clear that conscious sensations play a vital role in this case.

\section{Conclusion}

Once art is brought into the realm of science, several classical claims about it can be seen to be empirically testable. In his landmark work, Art and Experience, for example, John Dewey argues that aesthetic experience requires dissolution of self and object as separate existences. This stands in contrast with scientific observation, he notes, which calls for as much separation from subjectivity as possible in perceptual judgments. Empirical observation for the purposes of science idealizes a form of perception cleansed of the observer's expectations, personal desires, and preexisting beliefs. Any significant level of projection or interpretation skewed toward personal preferences, tastes, emotions, or remembrances is considered as tainting, or even invalidating, scientific observations. On the contrary, aesthetic experience depends, both ontologically and epistemologically, on such subjective contributions. Conscious or not, these sorts of differences should be quite measurable as differences in brain activity.

The hypothesis that specialized brain activity can be directly correlated with specific sorts of aesthetic responses received some confirmation by a recent experiment conducted by Kawabata and Zeki using functional magnetic resonance imaging (fMRI) to locate and quantify what they term 'neural correlates of beauty.' Prior to being scanned, their subjects classified paintings of different genres (abstract, still life, portrait, and landscape) as beautiful, neutral, or ugly. Subjects then viewed the same paintings while in the fMRI scanner. Distinct, specialized areas of the brain were found to be activated when perceiving different genres of painting. More interestingly, independent of the genre of the perceived painting, the orbitofrontal cortex was found to be differentially activated when the subject was perceiving beautiful or ugly stimuli, while the motor cortex was found to be activated differentially during perception of paintings as beautiful or ugly. Activity in the orbitofrontal cortex increased during the perception of beautiful stimuli and decreased in the case of ugly stimuli. The reverse was seen to be true of the motor cortex. Stimuli perceived as ugly produced the most activity while stimuli judged to be beautiful the least. That finding perhaps helps explain why aesthetic perception can sometimes have a curiously paralyzing effect on us, as Stendahl noted. Typically conscious experience induces one to act, whereas aesthetic experiences 'stop us in our tracks'; we end bodily motion to engage in deeper contact with the artwork. Aesthetic appreciation of this sort is not goal-oriented. If any action is motivated by aesthetic appreciation, it is to move closer to the art object, or at least to prolong the experience.

One often-heard objection, especially from the art establishment, is that neuroaesthetics is 'reductionist,' in the sense that its proponents intend to 
claim that the aesthetic experiences we are aware of are somehow unreal or unimportant, whereas the underlying brain events, as described by brain scientists, contain all the reality there is to them. The critics are forgetting, however, that science need not work this way. There is no reason in principle why understanding the phenomena underlying something should make our existing ways of understanding that thing go away. This only tends to happen when serious flaws are discovered in the existing ways of thinking and speaking, and this is not in general what is being proposed by the neuroaestheticians. This sort of noneliminative reduction can serve to ground aesthetic experience more firmly in scientific perceptives, making it more solid and real rather than less.

\section{Suggested Readings}

Aristotle (1984) In: Barnes J (ed.) Poetics, The Complete Works of Aristotle. Princeton, NJ: Princeton University Press.

Collingwood RG (1995) Principles of Art. Oxford: Clarendon Press.

Dewey J (1934) Art as Experience. New York: Perigee Books. Gombrich E (1956) Art and Illusion: A Study in the Psychology of Pictorial Representation. New York and London:
Andrew William Mellon Lectures in the Fine Arts, 5; Bollingen Series, 35: 5.

Gombrich E (1979) The Sense of Order, A Study in the Psychology of Decorative Art. Oxford: The Wrightsman Lectures.

Goodman N (1976) Languages of Art: An Approach to a Theory of Symbols. New York: Hackett.

Jackson F (1982) Epiphenomenal qualia. Philosophical Quarterly 32: 127-136.

Jackson F (1986) What Mary didn't know. The Journal of Philosophy LXXXIII 5: 291-295.

Kawabata H and Semir Z (2004) Neural correlates of beauty. Journal of Neurophysiology 91: 1699-1705.

Kant I (1790) In: Nicholas W (ed.) The Critique of Judgment. Oxford: Oxford University Press.

Onians J (2007) Neuroarthistory: From Aristotle and Pliny to Baxandall and Zeki. New Haven and London: Yale University Press.

Plato (2002) In: Cooper JM (ed.) Complete Works. New York: Hackett.

Ramachandran VS (2004) A Brief Tour of Human Consciousness. New York: Pi Press.

Rizzolatti $G$ and Craighero L (2004) The mirror neuron system. Annual Reviews of Neuroscience 27: 169-192.

Sacks O (2007) Musicophilia: Tales of Music and the Brain. New York: Knopf.

Stafford BM (2007) Echo Objects: The Cognitive Work of Images. Chicago, IL: Chicago University Press.

Wollheim R (1980) Art and lts Objects. Cambridge: Cambridge University Press.

Zeki S (2000) Inner Vision: An Exploration of Art and the Brain. Oxford: Oxford University Press.

\section{Biographical Sketch}

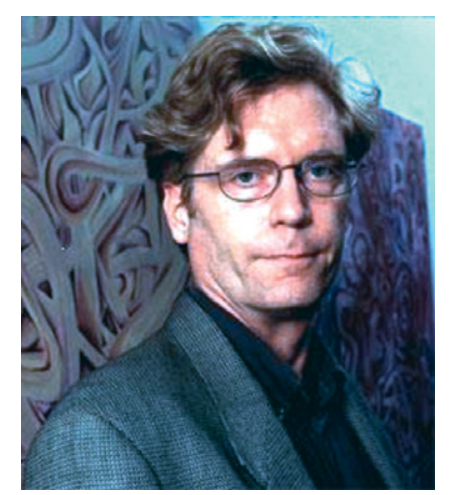

William Hirstein is professor and chair of the philosophy department at Elmhurst College, in Elmhurst, Illinois, USA. He received his PhD from the University of California, Davis, in 1994. His graduate and postdoctoral studies were conducted under the supervision of John Searle, V.S. Ramachandran, and Patricia Churchland. He is the author of several books, including On the Churchlands (Wadsworth, 2004), and Brain Fiction: Self-Deception and the Riddle of Confabulation (MIT, 2005). 


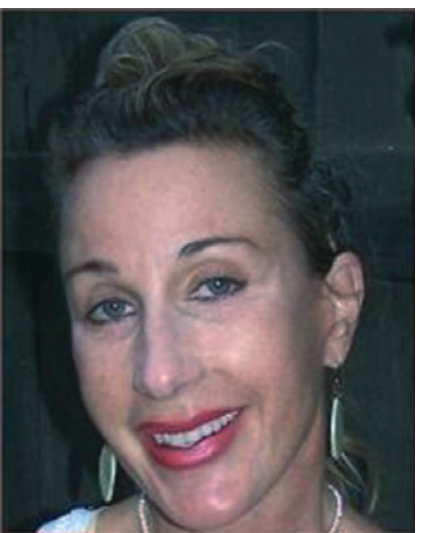

Melinda Campbell is associate faculty in arts and humanities at National University and also teaches courses in philosophy and women's studies at San Diego Mesa College. She is an artist and the author of several articles on the metaphysics of color. She studied with Richard Wollheim and received her PhD from the University of California, Davis, in 1993. 